\title{
Synergistic Brønsted/Lewis Acid Catalyzed Aromatic Alkylation with Unactivated Tertiary Alcohols or Di-tert-Butylperoxide to Synthesize Quaternary Carbon Centers
}

\begin{abstract}
Aaron Pan, ${ }^{+a}$ Maja Chojnacka, ${ }^{+a}$ Robert Crowley III, ${ }^{a}$ Lucas Göttemann, ${ }^{a}$ Brandon E. Haines ${ }^{b}$ and Kevin G. M. Kou*a

Dual Brønsted/Lewis acid catalysis involving environmentally benign, readily accessible protic acid and iron promotes siteselective tert-butylation of electron-rich arenes using di-tert-butylperoxide. This transformation inspired the development of a synergistic Brønsted/Lewis acid catalyzed aromatic alkylation that fills a gap in the Friedel-Crafts reaction literature by employing unactivated tertiary alcohols as alkylating agents, leading to new quaternary carbon centers. Corroborated by DFT calculations, the Lewis acid serves a role in enhancing the acidity of the Brønsted acid. The use of non-allylic, nonbenzylic, and non-propargylic tertiary alcohols represents an underexplored area in Friedel-Crafts reactivity.
\end{abstract}

\section{Introduction}

The simplicity and efficiency of $\mathrm{sp}^{2}-\mathrm{sp}^{2}$ cross-coupling technologies have driven its widespread adoption by the synthetic community, influencing synthesis strategies and the types of molecules that are most readily synthesized by the pharmaceutical industry. However, as a community, we are realizing trends that indicate enhanced developability and clinical success of organic molecules that exhibit greater degrees of saturation, which is often correlated with increasing numbers of $\mathrm{sp}^{3}$-hydridized carbons. ${ }^{1}$ This 'molecular complexity' tends to improve a compound's aqueous solubility, crystallinity, and binding specificity. ${ }^{2}$ All-carbon quaternary centers are frequently encountered in bioactive natural products, pharmaceuticals, and drug candidates (Figure 1). ${ }^{3}$

In a recent analysis of modern Negishi, Suzuki, and various nickel-catalyzed photoredox cross-coupling methods for constructing $\mathrm{C}\left(\mathrm{sp}^{2}\right)-\mathrm{C}\left(\mathrm{sp}^{3}\right)$ aryl-alkyl bonds by Abbvie scientists, none were able to install a tert-butyl group. ${ }^{2 b}$ This highlights the challenges inherent in synthesizing quaternary carbon centers, as well as the limitations that exist even with state-of-the-art catalysis. As such, considerable efforts have been devoted to their catalytic synthesis with precious metals, where palladium, rhodium, and iridium demonstrate the greatest utility. ${ }^{4}$

Modern variations of $\mathrm{Kumada}^{5}$ and Suzuki reactions, ${ }^{6}$ including photoredox-mediated, ${ }^{7}$ reductive $^{8}$ and redox-active ester-mediated cross-couplings ${ }^{9}$ have demonstrated success in

\footnotetext{
a. Department of Chemistry, University of California, Riverside, 501 Big Springs

Road, Riverside, CA 92521, USA. E-mail: kevin.kou@ucr.edu.

b. Department of Chemistry, Westmont College, 955 La Paz Road, Santa Barbara, CA

93108, USA.E-mail:bhaines@westmont.edu.

+ Denotes equal contributions.

Electronic Supplementary Information (ESI) available: Experimental procedures, characterization and X-ray crystallographic data.
}

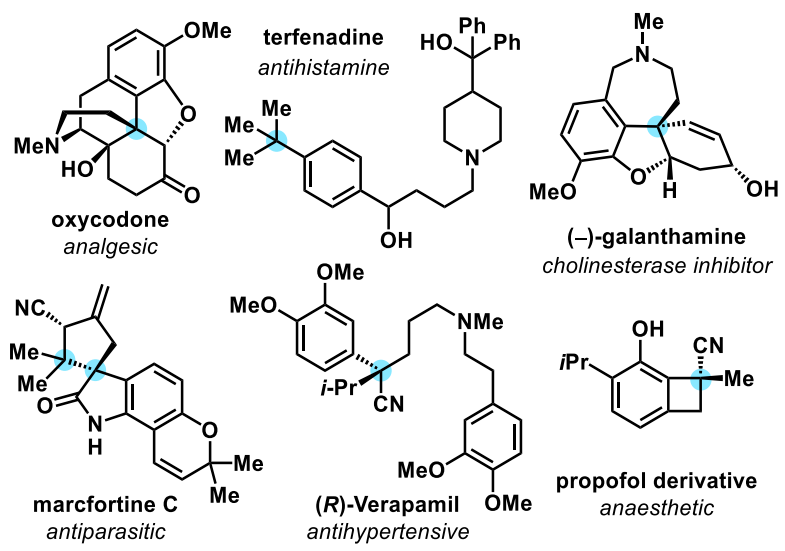

Figure 1. Bioactive molecules bearing all-carbon quaternary carbon centers.

merging $\mathrm{C}\left(\mathrm{sp}^{2}\right)$ and $\mathrm{C}\left(\mathrm{sp}^{3}\right)$ units to forge new all-carbon quaternary centers. While the development of nickel ${ }^{5-11}$ and copper $^{12}$ catalyses for synthesizing quaternary carbon centers have progressed in recent years, examples with other abundant transition metals such as iron, are scarce. ${ }^{13}$ In considering new solutions to quaternary carbon synthesis, we surmised that a Friedel-Crafts approach would effectively permit direct $\mathrm{C}-\mathrm{H}$ functionalization. In this respect, Beller and coworkers reported primary and secondary, benzylic halides/acetates/alcohols coupling with arenes under iron catalysis (Scheme 1). ${ }^{14}$ The Cook group found that in conjunction with a silver salt, $\mathrm{FeCl}_{3}$ promotes Friedel-Crafts reactions between arenes and unactivated secondary alcohols. ${ }^{15}$ Herein, we disclose a Fentoninspired, synergistic Brønsted/Lewis acid-catalysis ${ }^{16}$ that enables aromatic alkylation with unactivated tertiary alcohols. These findings represent underexplored examples of using nonbenzylic, non-propargylic, and non-allylic alcohols for Friedel- 


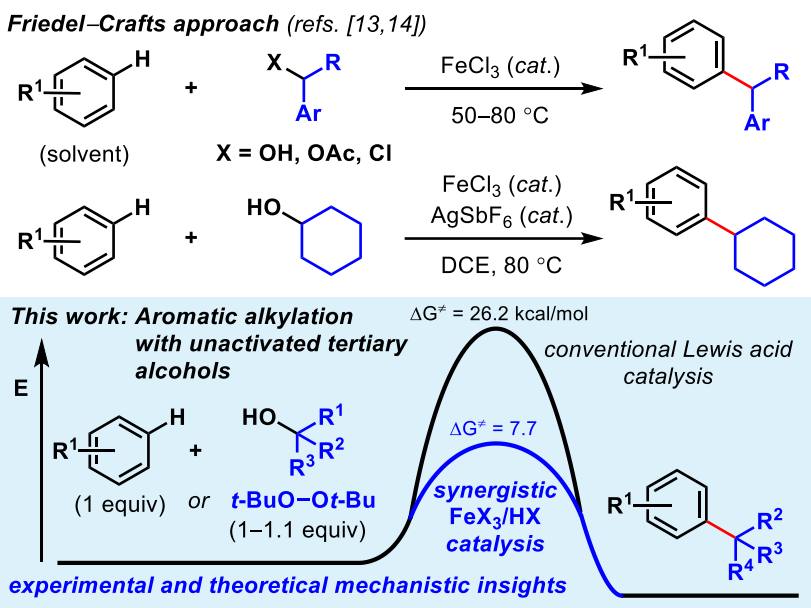

Scheme 1. Synergistic iron/TFA-catalyzed tert-butylation of phenol using peroxide reagents with and without an acid co-catalyst.

Crafts-type alkylations. ${ }^{17,18}$ The use of environmentally benign, readily accessible reagents and catalysts provides a green approach to quaternary carbon synthesis.

\section{Results and Discussion}

The Fenton reaction is a classic iron-catalyzed oxidation that employs peroxide reagents and a strong acid. ${ }^{19}$ Its reactivity has been elegantly exploited for aliphatic $\mathrm{C}-\mathrm{H}$ functionalization to synthesize $\mathrm{C}-\mathrm{O}^{20}$ and $\mathrm{C}-\mathrm{S}^{21}$ bonds. In our investigations of the reactivity of aromatic $\mathrm{C}-\mathrm{H}$ bonds under Fenton-inspired conditions, we observed that the treatment of phenol (1) with equimolar di-tert-butyl peroxide (DTBP, 2), trifluoroacetic acid, and catalytic $\mathrm{FeCl}_{3}$, led to site-selective $\mathrm{C}-\mathrm{C}$ formation in 4-tertbutylphenol (3a) with 5:1 para/ortho selectivity (Scheme 2). This dual Brønsted/Lewis acid catalysis exerts considerably enhanced reactivity and selectivity with a related, but unselective, iron-mediated system where the arene reagent was employed as the solvent. ${ }^{22}$

Selective tert-butylation via dual Brønsted/Lewis acid conditions extend to other phenolic derivatives (Scheme 3). Substituted phenolic and anisolic substrates generally alkylate to yield one major isomeric product. Exposing 4-tertbutylphenol to DTBP (2) in the presence of iron(III) and $\mathrm{HCl}$ catalysts yields $73 \%$ of 2,4-di-tert-butylphenol (3ba). 4-Chloroand 4-fluorophenols require stoichiometric iron salts to proceed and are transformed into their alkylated counterparts 3ca and 3da in $41 \%$ and $64 \%$ yields, respectively. Under these reaction conditions, overoxidation to benzoquinone-type sideproducts accounts for some of the mass balance. meta-

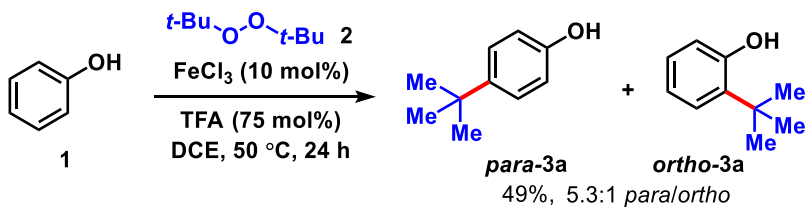

Scheme 2. Synergistic Iron/TFA-catalyzed tert-butylation of phenol using peroxide reagents with and without an acid co-catalyst.
Substituted phenols are alkylated exclusively at the lesshindered position(s) ortho to the phenolic group. Both 3-ethyl and 3-tert-butylphenol are converted to tert-butylated 3ea and 3 fa in $58 \%$ and $92 \%$ yields, respectively, the latter of which is confirmed by X-ray crystallography (see $\mathrm{SI}$ ). The higher isolated yield obtained for $\mathbf{3} \mathbf{f a}$ is presumably due to the lack of benzylic hydrogens that can participate in hydrogen atom abstractions. 3-Phenylphenol, which also does not contain benzylic hydrogens, is transformed into the corresponding alkylated product (3ga) in $73 \%$ yield. The phenolic derivative bearing a meta-chloro substituent undergoes tert-alkylation to yield phenolic 3ha in a modest $41 \%$ yield. Contrary to phenolic substrates $\mathbf{1} \mathbf{a}-\mathbf{h}$ that are monoalkylated at the less hindered ortho site, 3-methoxy- and 3-fluorophenol are tert-butylated at both the 4- and 6-positions to furnish tetrasubstituted phenols 3iaa and 3jaa, in $90 \%$ and $62 \%$ yields, respectively, with 1 equivalent of DTBP (2). ortho-Substituted phenolic substrates are considerably less reactive but are selectively tert-butylated para to the hydroxy group to yield 3ba, 3ka and 3la in 22-44\% yields when conditions involving higher iron loadings and extended reaction times are used.

Aryl ether and thiophene derivatives are better behaved in the dual iron(III)/HCl catalyzed tert-butylation reaction (Scheme 3 ). Anisole is converted to 4-tert-butylanisole (4ma) in $73 \%$ yield. 2,4-Dialkylation occurs with bromopropyl phenyl ether to afford trisubstituted arene 4 naa in $48 \%$ yield, with no monoalkylation product observed. ortho-Substituted anisole precursors are site-selectively functionalized para to the methoxy group. Unlike the 2- alkylphenolic derivatives, which are poorly reactive, 2-methyl- and 2- ethylanisoles undergo tertbutylation to give $40 \mathrm{oa}$ and $\mathbf{4 p a}$ in $83 \%$ and $88 \%$ yields, respectively. Anisole derivatives with an aliphatic alcohol or bromo group at the 2-position are transformed to their corresponding tert-butylated products in moderate yields $(45 \%$ for $\mathbf{4 q a}$ and $53 \%$ for $\mathbf{4 r a})$. New $\mathrm{C}\left(\mathrm{sp}^{2}\right)-\mathrm{C}\left(\mathrm{sp}^{3}\right)$ bond formation occurs with benzodioxole, albeit less effectively than with anisole, producing 4 sa in $50 \%$ yield. 3-Substituted aryl ethers are functionalized selectively to products 4 ta and 4 ua with alkylation at the ortho positions in $68-73 \%$ yields. Selective mono-tert-butylation proceeds with 4-tert-butylanisole to deliver 2,4-di-tert-butylanisole (4va) in $75 \%$ yield. An anisole derivative bearing a pendant ester group is accommodated and $54 \%$ of the alkylated product (4wa) is formed. In addition to anisole derivatives, thiophene derivatives react effectively. Treating 3-hexylthiophene with DTBP (2) under iron(III)/HCl catalysis favors di-tert-butylation at both the 2-and 5-positions (4xaa, 82\%), whereas the analogous reaction with benzothiophene leads to selective tert-butylation at the 3position in $76 \%$ yield (4ya). In contrast, the phosphoric acidmediated direct alkylation of thiophene derivatives with tertbutanol requires $200{ }^{\circ} \mathrm{C}$ to achieve modest yields. ${ }^{23}$

The dual Brønsted/Lewis acid-catalyzed cross-coupling between electron-rich arenes and DTBP (2) represents an underexplored site-selective Friedel-Crafts alkylation process. However, the modest reactivity experienced by several substrates and the reliance on DTBP (2) limit synthetic practicality. We speculate side reaction pathways arising from 


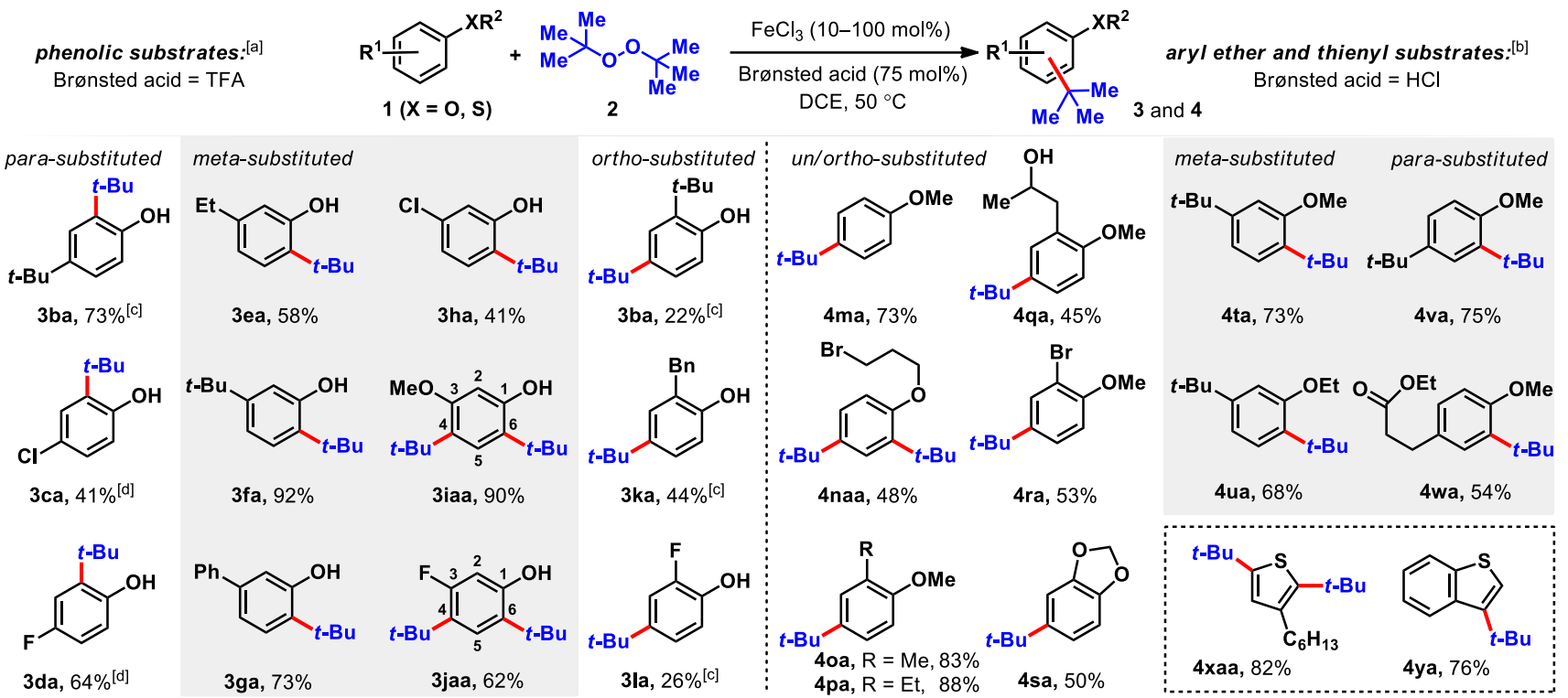

Scheme 3. Scope of tert-butylation of phenolic, aryl ether, and thiophene derivatives. [a] Reaction conditions: arene 1 (0.2 $\mathrm{mmol}), \mathrm{DTBP}(2,0.2 \mathrm{mmol}), \mathrm{FeCl}{ }_{3}(10$ $\mathrm{mol} \%)$, TFA $(0.15 \mathrm{mmol}), \mathrm{DCE}(0.8 \mathrm{~mL}), 50^{\circ} \mathrm{C}, 2 \mathrm{~h}$. [b] Reaction conditions: arene $1(0.2 \mathrm{mmol}), \mathrm{DTBP}(2,0.2 \mathrm{mmol}), \mathrm{FeCl}(30 \mathrm{~mol} \%), \mathrm{TFA}(0.15 \mathrm{mmol}), \mathrm{DCE}(0.8$ $\mathrm{mL}), 50^{\circ} \mathrm{C}, 2 \mathrm{~h}$. [c] $\mathrm{FeCl}_{3}(20 \mathrm{~mol} \%), 18 \mathrm{~h}$. [d] $\mathrm{FeCl}_{3}$ (1 equiv), $\mathrm{HCl}_{(\mathrm{aq})}(0.15 \mathrm{mmol}), 48 \mathrm{~h}$.

radical species compromise reactivity and product yields. In a proposed pathway analogous to that with hydrogen peroxide (Scheme 4a), ${ }^{24}$ DTBP (2) can react with iron(III) to form iron(III) tert-butylperoxide (5) and tert-butyl cation (6), the latter of which can participate in the desired electrophilic alkylation. Single electron transfer with the former would lead to iron(II) and tert-butylperoxyl radical (7), which could abstract a hydrogen atom from the solvent or substrate to give tert-butyl hydroperoxide (8). Alternatively, iron(II) produced in this manner, or through reduction of iron(III) by phenol and anisole derivatives, ${ }^{25,26}$ can reduce DTBP (2) in a Fenton-like fashion to generate iron(III) (9) and tert-butoxyl radical (10, Scheme 4b). Subsequent hydrogen atom abstraction by the oxygen-centered
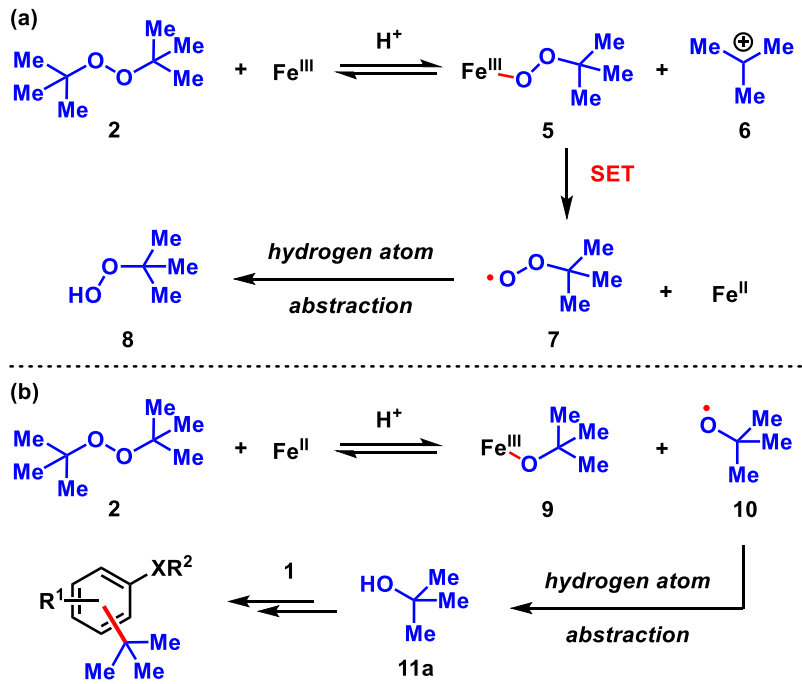

Scheme 4. Proposed pathways for the decomposition of DTBP (2). (a) $\mathrm{Fe}$ (III) initiated pathway. (b) Fe(II) initiated pathway. radical may initiate undesirable side reactions while producing tert-butanol (11a), a potential precursor to the desired FriedelCrafts reaction. We find catalysis with $\mathrm{FeCl}_{2}$ proceeds similarly to $\mathrm{FeCl}_{3}$, which is consistent with a Fenton-initiation process. A kinetic analysis was undertaken to derive insight into optimizing the $\mathrm{C}\left(\mathrm{sp}^{2}\right)-\mathrm{C}\left(\mathrm{sp}^{3}\right)$ cross-coupling reaction. 3-tert-Butylphenol (1f) was selected as the model substrate to react with DTBP (2) because little-to-no side products form over the course of the reaction, thus simplifying the data analysis and interpretation. Initial rates for tert-butylation were then measured by varying the concentrations 1f, DTBP (2), TFA, and $\mathrm{FeCl}_{3}$ catalyst. A firstorder rate dependence on the concentration of phenolic $\mathbf{1 f}$ was
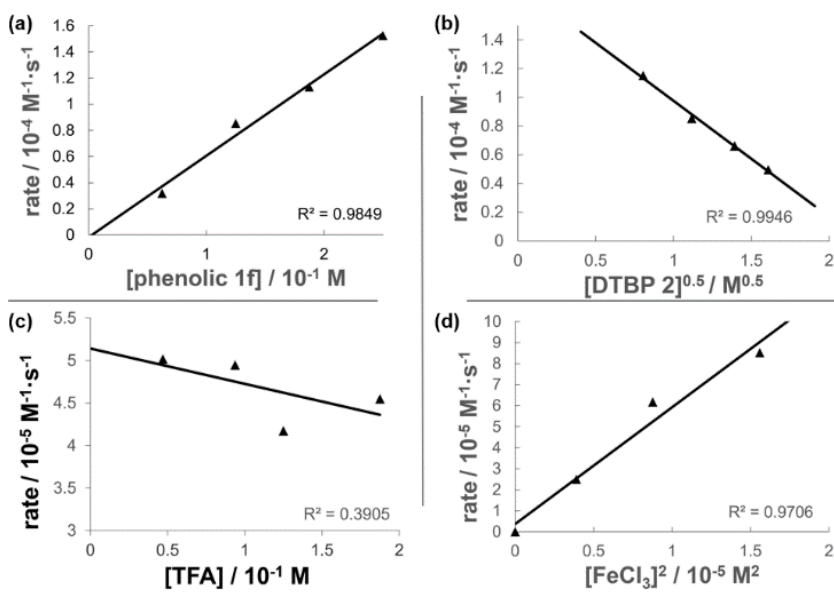

Figure 2. Plots of initial rates with respect to (a) [3-tert-butylphenol 1f] indicating approximate first-order dependence, $\left[\right.$ DTBP 2] $=0.13 \mathrm{M},\left[\mathrm{FeCl}_{3}\right]=0.012 \mathrm{M}$, [TFA] $=0.094 \mathrm{M}$; (b) [DTBP 2 $]^{0.5}$ indicating half-order dependence, $[\mathbf{1 f}]=0.12 \mathrm{M},\left[\mathrm{FeCl}_{3}\right]$ $0.012 \mathrm{M},[\mathrm{TFA}]=0.094 \mathrm{M}$; (c) [TFA] suggestive of zero-order dependence, [1f] = $0.12 \mathrm{M},[\mathrm{DTBP} 2]=0.13 \mathrm{M},\left[\mathrm{FeCl}_{3}\right]=0.012 \mathrm{M} ;(\mathrm{d})\left[\mathrm{FeCl}_{3}\right]^{2}$ indicating second-order dependence, $[1 \mathrm{f}]=0.12 \mathrm{M},[\mathrm{DTBP}]=0.13 \mathrm{M},[\mathrm{TFA}]=0.094 \mathrm{M}$. Each data point was measured in triplicate. 

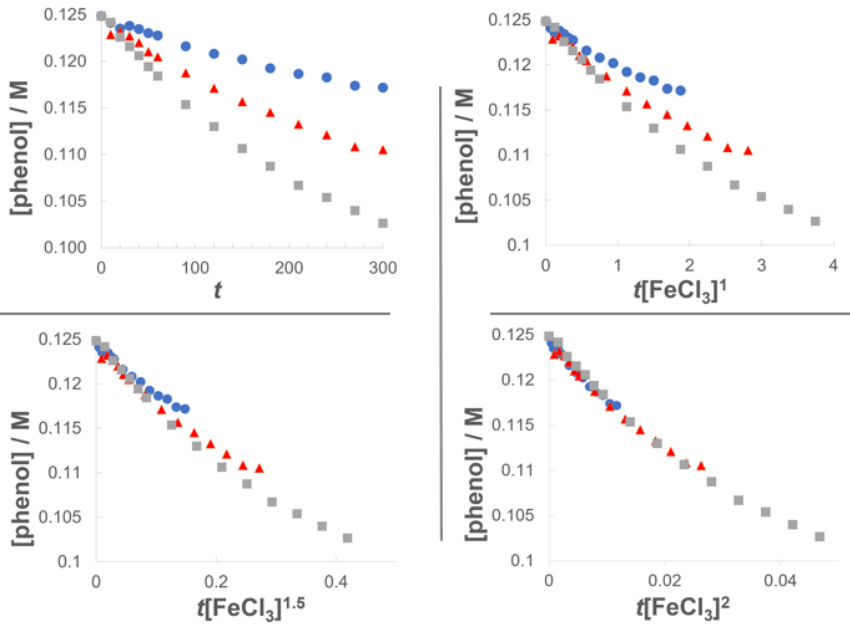

Figure 3. Plots of the normalized time scale method for determining catalys order; Blue $=0.0062 \mathrm{M} \mathrm{FeCl}_{3}$, Orange $=0.0094 \mathrm{M} \mathrm{FeCl}_{3}$, Grey $=0.013 \mathrm{M} \mathrm{FeCl}_{3}$.

observed (Figure 2a). The kinetics experiments revealed a halforder dependence with respect to the concentration of DTBP(2) (Figure 2b), suggestive of $\mathbf{2}$ dissociating into two active fragments and consistent with the mechanistic hypotheses presented in Scheme 4. Little change in initial rates were observed with varying TFA concentrations, which we interpret as zero-order rate dependence (Figure $2 \mathrm{c}$ ). With respect to $\mathrm{FeCl}_{3}$, a relatively uncommon second order dependence on rate was observed (Figure 2d). Additional evidence for the catalyst order was sought by treating the reaction profile data to graphical analysis using the normalized time scale method. ${ }^{27}$ Rather than converting the raw data to rates, the raw concentration data of the entire data sets (i.e., [1f]) are plotted against normalized time scales, $t \cdot\left[\mathrm{FeCl}_{3}\right]^{n}$, where $t=$ time and $n$ corresponds to the catalyst order when all the curves overlay on one another (Figure 3). Using the data sets obtained from varying the catalyst loadings, the curves overlay when $n=2$, which support a second order dependence in $\left[\mathrm{FeCl}_{3}\right]$ and is consistent with the catalyst playing distinct roles in transforming DTBP (2) into the reactive alkylating agent, potentially tert-butanol (11a), and further activating it for merger with the arene coupling partner. Based on this mechanistic conjecture, DTBP (2) should be replaceable by tertalkanols. While catalytic tert-alkylations using allylic, propargylic, and benzylic alcohols are well precedented, ${ }^{18}$ few examples exist with unactivated tert-alkanols, especially in the context of site-selectivity. Successful tert-butylation has been reported with superstoichiometric amounts of strong acid ${ }^{28}$ or super acids. ${ }^{23,29,30}$ We envisage that the process involving a synergistic combination of $\mathrm{Fe}(\mathrm{III})$ and Brønsted acid catalysts would address the synthetic limitations imposed by using peroxides as coupling reagents, and would provide a simple approach for directly forging $C\left(s p^{2}\right)-C\left(s p^{3}\right)$ bonds with quaternary carbon centers.

We targeted the joining of 2-methyl-2-butanol (11b) and 3tert-butylphenol (1f) to investigate our hypothesis (Table 1). The use of $2.5 \mathrm{~mol}^{\circ} \mathrm{FeCl}_{3}$ and $75 \mathrm{~mol} \% \mathrm{HCl}$ in DCE solvent afforded $72 \%$ yield of target $\mathbf{3} \mathrm{fb}$ (entry 1 ). In contrast to the reactions with DTBP (2), tert-alkylation does not occur with trifluoroacetic acid as the co-catalyst (entry 2), while 66\% NMR yield was obtained with $\mathrm{HBr}$ (entry 3). Using $\mathrm{FeCl}_{2}$ instead of $\mathrm{FeCl}_{3}$ resulted in a significant drop in conversion to $15 \%$ (entry 4). $\mathrm{FeBr}_{3}$ (entry 5) and $\mathrm{FeBr}_{2}$ (entry 6) performed similarly to $\mathrm{FeCl}_{3}$ (70\% yields). Increasing or decreasing the amounts of acid led to inferior $63 \%$ and $60 \%$ yields, respectively (entries 7 and 8). Exchanging the solvent for HFIP resulted in only $13 \%$ conversion (entry 9). The reaction proceeded similarly in chlorobenzene solvent (75\%, entry 10$)$. When performed in toluene, moderate levels of product formation were observed ( $43 \%$, entry 11$)$; the lower yield is attributed to toluene being reactive, which consumes a significant proportion of the alcohol (see Scheme 8). Isopropanol and THF solvents do not promote the desired alkylation (entries 12 and 13). Considering reagent cost and operation simplicity, we elected to use $\mathrm{FeCl}_{3}, \mathrm{HCl}$, and DCE solvent as the optimal conditions to explore the substrate scope. These reactions can be set up under air. Moisture does not affect reactivity and aqueous $\mathrm{HCl}$ can be used as the source of Brønsted acid. The unique reactivity arising from the combination of $\mathrm{FeCl}_{3}$ and $\mathrm{HCl}$ previously observed in a cation- $\pi$ polycyclization has been attributed to the formation of $\mathrm{HFeCl}_{4} \cdot{ }^{31}$ The desired tert-alkylation reactions are not restricted to phenolic compounds, but also to anisolic and electron-neutral arenes, in which cases the combination of $\mathrm{FeBr}_{3}$ and $\mathrm{HBr}$

Table 1. Survey of conditions for direct Friedel-Crafts alkylation with phenolic $\mathbf{1 f}$ and tertiary alcohol 11b. [a]

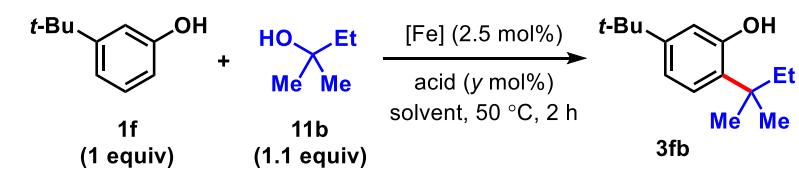

\begin{tabular}{cccccc}
\hline & {$[\mathrm{Fe}]$} & acid & $\boldsymbol{y}$ & solvent & \% yield ${ }^{[\mathrm{b}]}$ \\
\hline 1 & $\mathrm{FeCl}_{3}$ & $\mathrm{HCl}_{(\mathrm{aq})}$ & 75 & $\mathrm{DCE}$ & $72(10)^{[\mathrm{c}]}$ \\
2 & $\mathrm{FeCl}_{3}$ & $\mathrm{CF}_{3} \mathrm{COOH}$ & 75 & $\mathrm{DCE}$ & 0 \\
3 & $\mathrm{FeCl}_{3}$ & $\mathrm{HBr}_{(\mathrm{aq})}$ & 75 & $\mathrm{DCE}$ & 66 \\
4 & $\mathrm{FeCl}_{2}$ & $\mathrm{HCl}_{(\mathrm{aq})}$ & 75 & $\mathrm{DCE}$ & 15 \\
5 & $\mathrm{FeBr}_{3}$ & $\mathrm{HCl}_{(\mathrm{aq})}$ & 75 & $\mathrm{DCE}$ & 70 \\
6 & $\mathrm{FeBr}_{2}$ & $\mathrm{HCl}_{(\mathrm{aq})}$ & 75 & $\mathrm{DCE}$ & 70 \\
7 & $\mathrm{FeCl}_{3}$ & $\mathrm{HCl}_{(\mathrm{aq})}$ & 50 & $\mathrm{DCE}$ & 63 \\
8 & $\mathrm{FeCl}_{3}$ & $\mathrm{HCl}_{(\mathrm{aq})}$ & 100 & $\mathrm{DCE}$ & 60 \\
9 & $\mathrm{FeCl}_{3}$ & $\mathrm{HCl}_{(\mathrm{aq})}$ & 75 & $\mathrm{HFIP}$ & 13 \\
10 & $\mathrm{FeCl}_{3}$ & $\mathrm{HCl}_{(\mathrm{aq})}$ & 75 & $\mathrm{PhCl}$ & 75 \\
11 & $\mathrm{FeCl}_{3}$ & $\mathrm{HCl}_{(\mathrm{aq})}$ & 75 & PhMe & 43 \\
12 & $\mathrm{FeCl}_{3}$ & $\mathrm{HCl}_{(\mathrm{aq})}$ & 75 & IPA & 0 \\
13 & $\mathrm{FeCl}_{3}$ & $\mathrm{HCl}_{(\mathrm{aq})}$ & 75 & THF & 0 \\
\hline
\end{tabular}

[a] Conditions: All reactions performed on $0.2 \mathrm{mmol}$ scale, phenol (1 equiv), alcohol (1.1 equiv), $0.25 \mathrm{M}, 50{ }^{\circ} \mathrm{C}, 24 \mathrm{~h}$. [b] Determined by NMR analysis of the crude reaction mixture using 1,3,5trimethoxybenzene as the internal standard. [c] Without Brønsted acid. 


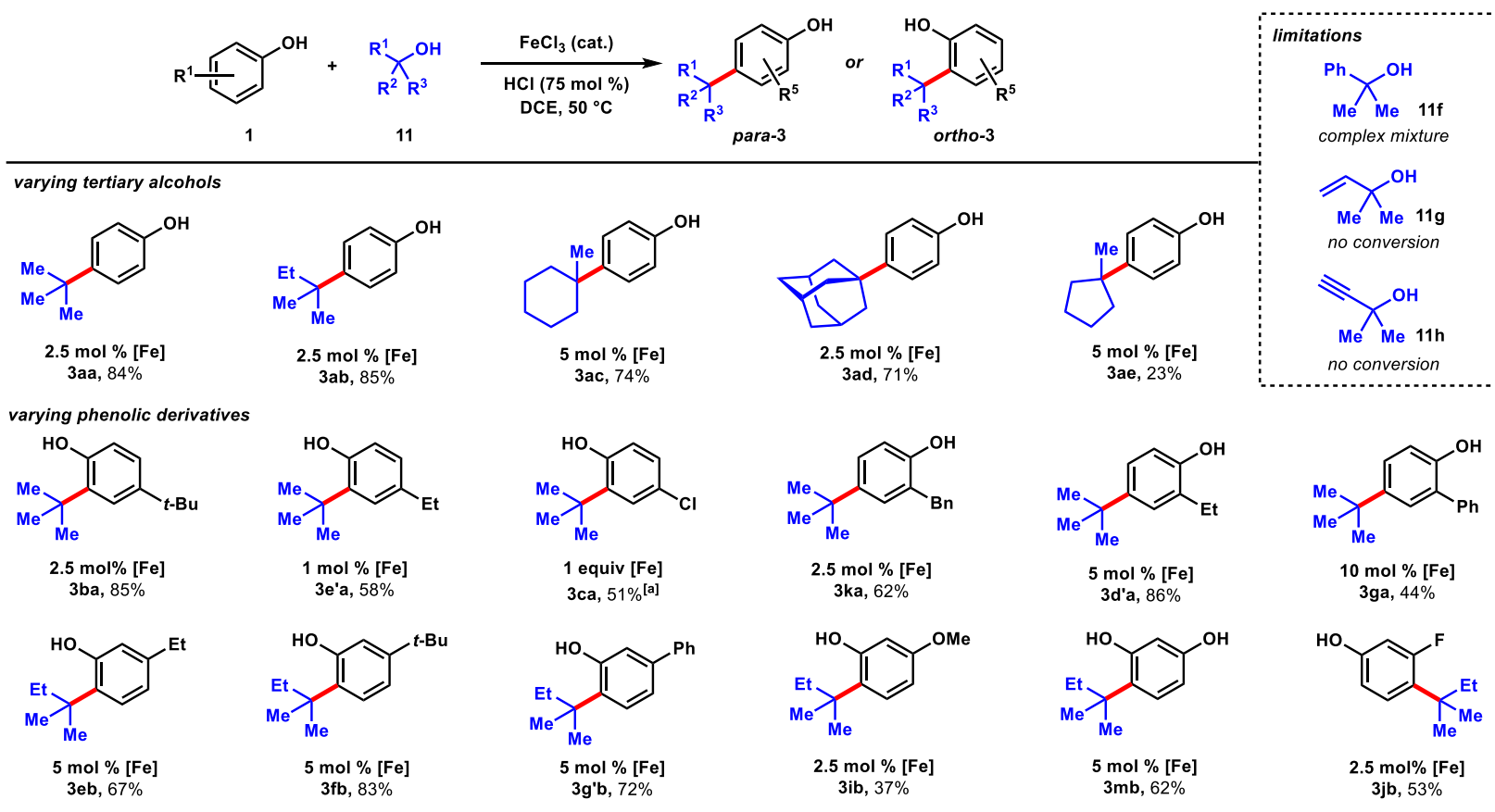

Scheme 5. Scope of dual Brønsted/Lewis acid-catalyzed, $\mathrm{C}\left(\mathrm{sp}^{2}\right)-\mathrm{C}\left(\mathrm{sp}^{3}\right)$ coupling between phenolic and tertiary alcohol derivatives. [a] 2 equiv $11 \mathrm{a}, 48 \mathrm{~h}$.

catalysts were found to be the optimal catalysts (See SI for optimization studies). Product formation was not observed in the absence of iron catalyst and the use of $\mathrm{AlCl}_{3}$ in place of $\mathrm{FeX}_{3} / \mathrm{HX}$ resulted in complex mixtures.

The ability to use tertiary alcohols enables various alkyl groups to be added (Scheme 5). Alkylation of phenol (1) occurred selectively at the para position, affording 3aa-3ad in $71-85 \%$ yields. Adamantane is a privileged structure that has earned the reputation of being a "lipophilic bullet" for enhancing pharmacological activity ${ }^{32}$ and various methods have been devised for their derivatization, ${ }^{33}$ including a FriedelCrafts strategy that requires trifluoroacetic acid as the solvent. ${ }^{34}$ Here, dual $\mathrm{FeCl}_{3} / \mathrm{HCl}$ catalysis allows arylation of 1-adamantanol under mild reaction conditions. Surprisingly, 1methylcyclopentanol (11e) turned out to be a poor alkylating agent that only gave $23 \%$ yield of para-methylcyclopentyl phenol (3ae) even with a higher catalyst loading. Analysis of the reaction mixture revealed the major side product to be cyclopentene. Presumably, the dehydration pathway is facile, and the reverse hydration step is unfavorable under the reaction conditions. Using tert-butanol (11a), alkylation of 4tert-butylphenol furnishes di-tert-butylphenol (3ba) in $85 \%$ yield, while 4-ethylphenol was alkylated to yield 3e'a in 58\% yield at $1 \mathrm{~mol}^{\circ} \mathrm{FeCl}_{3}$ loading. 4-Chlorophenol required 1 equivalent of $\mathrm{FeCl}_{3}$ to achieve $51 \%$ yield of 3ca. 2-Benzyl-, 2ethyl-, and 2-phenylphenol were alkylated in moderate-to-good yields (62-86\%) to give 3ka, 3d'a, and 3ga, respectively. Some substrates require higher catalyst loadings (e.g., 2-ethylphenol and 2-phenylphenol) to achieve high reactivity, but absent of a trend. Minor amounts of dialkylation side products were isolated (see SI). tert-Alkylation of meta-substituted phenols were examined using 2-methyl-2-propanol (11b). At 5 mol\% catalyst loading, 3-ethyl-, 3-tert-butyl-, and 3-phenylphenol are converted to disubstituted phenols $\mathbf{3 e b}, \mathbf{3 f b}, \mathbf{3} \mathbf{g}^{\mathbf{\prime}} \mathbf{b}$ in $67-83 \%$ yields. 3-Methoxyphenol is converted to $3 \mathrm{ib}$ in $37 \%$ yield and alkylated resorcinol $3 \mathrm{mb}$ is synthesized in $62 \%$ yield. Unlike other meta-substituted phenols, 3-fluorophenol is tertalkylated para to the hydroxy group in $53 \%$ yield $(\mathbf{3} \mathbf{j b})$. Tertiary benzylic, allylic, and propargylic alcohols 11f-h, normally successful in Friedel-Crafts alkylations, either resulted in a complex mixture of products that could not be separated to homogeneity or no reactivity.

We next examined the alkylation of aryl ethers and simple arenes (Scheme 6). 3-tert-Butylanisole is selectively alkylated at the less sterically encumbered ortho position with respect to the methoxy group (4va, 75\%). Swapping the methyl ether with an ethyl ether yields product 4 ua in $86 \%$. However, 1,2benzodioxole (4sa) is tert-butylated in a modest $34 \%$ yield. A primary halide tethered off the ether linkage does not hinder the reaction and results in $94 \%$ yield of 4 na. A variety of tertiary alcohols were tested to alkylate 2-methylanisole (10). Most of the alcohols deliver the alkylated products (4oa-4od) in near quantitative yields (94-99\%) with low catalyst loadings: $1 \mathrm{~mol} \%$ for tert-butanol (11a) and tert-amyl alcohol (11b), and $10 \mathrm{~mol} \%$ for methylcyclohexanol (11c) and adamantanol (11d). Methylcyclopentanol (11e) and cumyl alcohol (11f), substrates that reacted poorly with phenol (cf. Scheme 5 ), requires 30 mol\% iron and yields alkylated 40 oe and 4 of in $73 \%$ and $59 \%$, respectively. Alkylation of 2-ethylanisole with methylcyclohexanol provides $4 \mathrm{pc}$ in $99 \%$ yield. 2-Bromoanisole is considerably less reactive, leading to alkylated 4 ra in $37 \%$ yield with a full equivalent of $\mathrm{FeBr}_{3}$. While most of the metasubstituted anisole derivatives are alkylated to 4ta, 4za, and 4z'a in moderate yields (56-75\%) with catalytic $\mathrm{FeBr}_{3}$, 3-iodo- 


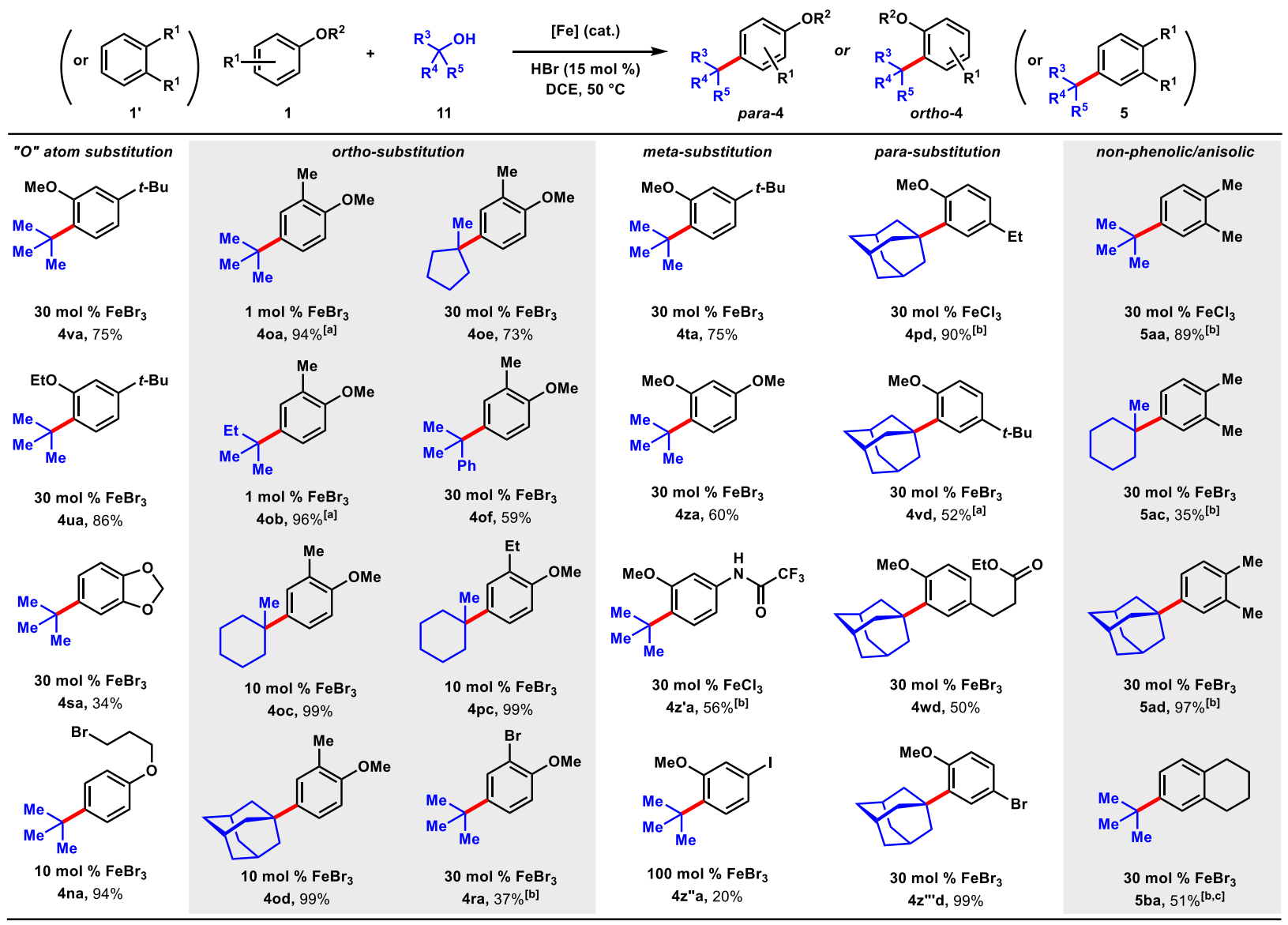

Scheme 6. Scope of dual Brønsted/Lewis acid-catalyzed, $\mathrm{C}\left(\mathrm{sp}^{2}\right)-\mathrm{C}\left(\mathrm{sp}^{3}\right)$ coupling of arene and tertiary alcohol derivatives. [a] $10 \mathrm{~mol} \% \mathrm{HBr}$. [b] $75 \mathrm{~mol} \% \mathrm{HCl}$. [c] Isolated as a 2.6:1 mixture of product/starting material.

anisole requires a full equivalent of $\mathrm{FeBr}_{3}$, and furnished the product (4z"a) in $20 \%$ yield. tert-Alkylation of 4-ethylanisole led to product 4 pd in $90 \%$ yield, but 4 -tert-butylanisole turned out to be a more challenging substrate, likely owing to the added steric bulk, forming alkylation product $\mathbf{4 v d}$ in $52 \%$ yield. The reaction accommodates esters, providing product $\mathbf{4} \mathbf{w d}$ in $50 \%$ yield. In contrast to previously studied halogenated arenes, 4bromoanisole was converted to product $\mathbf{4} \mathbf{z}^{\prime \prime \prime} \mathbf{d}$ in quantitative yield. This tert-alkylation reaction is not confined to phenolic and aryl ether substrates. ortho-Xylene and tetralin are alkylated to provide arenes 5aa, 5ac, 5ad, and 5ba in 35-97\% yields. In contrast to the $\mathrm{TFA} / \mathrm{FeCl}_{3}$ system where the kinetics are well-behaved (see Scheme 3 \& Figure 2), the occurrence of induction periods that complicate the kinetics analysis are observed with the $\mathrm{HCl} / \mathrm{FeCl}_{3}$ pair. The reaction rates during the acceleration periods following the induction periods are invariably constant and does not appear to be affected by concentrations of $\mathrm{FeCl}_{3}, \mathrm{HCl}$, phenolic substrate, nor $t$-butanol, thereby resembling zero-order behaviors in all cases (see $\mathrm{SI}$ ).

Several naturally occurring compounds were subjected to late-stage tert-alkylation (Figure 4). Initially, the compounds tested performed poorly due to low solubility in DCE at $50{ }^{\circ} \mathrm{C}$. However, useful yields resulted by changing the solvent to chlorobenzene and heating to $100{ }^{\circ} \mathrm{C}$. Thymol and sesamol are adamantylated to produce functionalized $\mathbf{1 2}$ and $\mathbf{1 3}$ in 38\% and $65 \%$ yields, respectively. The relatively more complex molecule, estrone, undergoes tert-butylation in $40 \%$ yield (14a) and adamantylation in $19 \%$ yield (14d).

To assess the stability of the tertiary alcohol under the reaction conditions, we exposed 1-adamantanol (11d) to dual Brønsted/Lewis acid catalysis conditions (Scheme 7a). In the absence of the arene substrate, 1-bromoadamantane (15) was isolated in $28 \%$ yield. Subjecting the same reaction to 1 equivalent of $\mathrm{FeBr}_{3}$ increased the yield to $87 \%$. To probe whether the reaction proceeds through a closed- or open-shell pathway, we investigated the capturing of putative radical intermediates using various Michael acceptors 17 (Scheme 7b). The potential for a 1-electron reduction of the newly formed

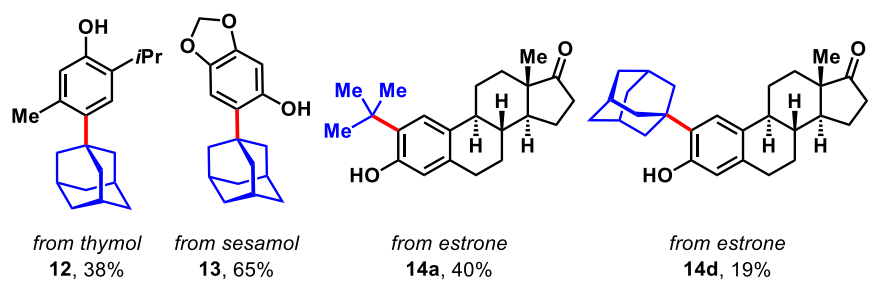

Figure 4. Late-stage tert-alkylation of natural products. Conditions: $\mathrm{FeCl}_{3}(5 \mathrm{~mol} \%)$, tert-alcohol (1.1 equiv), $\mathrm{HCl}(75 \mathrm{~mol} \%), \mathrm{PhCl}, 100{ }^{\circ} \mathrm{C}$. 
(a)

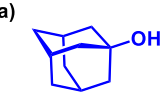

$\underset{\mathrm{FeBr}}{\mathrm{FBr}_{3}(x \mathrm{~mol} \%),}$
$\underset{\mathrm{DCE}, 50^{\circ} \mathrm{C}}{\mathrm{HBr}}($ equiv $)$

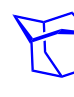

$11 \mathrm{~d}$

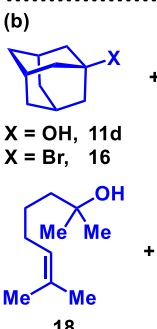

18
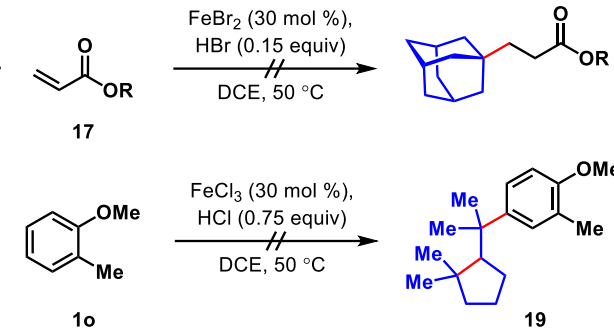

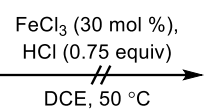

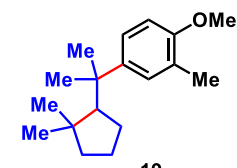

10
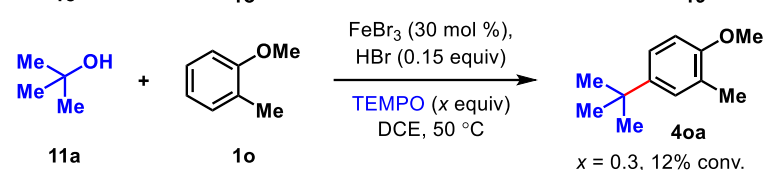
$x=0.3,12 \%$ conv. $x=1, \quad 0 \%$ conv.

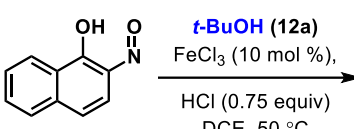

20

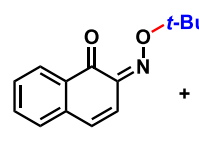

$21(18 \%)$

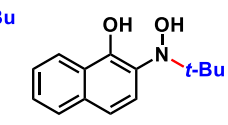

22 (not observed)

Scheme 7. (a) Fate of the alcohol. (b) Probing for a radical vs polar pathway.

carbon-halogen bond using an iron (II) catalyst was examined. However, attempts to generate radical species from both 1adamantanol (11d) and 1-bromoadamantane (15) were deemed unsuccessful because we were unable to observe any alkyl addition to the Michael acceptors. Initially, methyl acrylate and phenyl acrylate were tested, however both proved ineffective, as did others that were investigated (see $\mathrm{SI}$ ). If a radical intermediate forms from alkenol 18, the resulting tertiary radical could cyclize onto the alkene but attempts to react it with 2-methylanisole (10) resulted in a mixture of products with no indication of cyclization to cyclopentyl 19. Addition of substoichiometric TEMPO reduced reactivity to $12 \%$ conversion and stoichiometric TEMPO halted reactivity. However, in the absence of other compelling data, we interpret this as a competitive interaction between TEMPO and the iron reagent that leads to catalyst arrest. ${ }^{35}$ This is supported by the lack of TEMPO-adducts observed, which are otherwise expected to form from the quenching of arene radical or tertiary alkyl radical species. While less common than TEMPO, nitroso compounds exert radical scavenging properties. ${ }^{36}$ As such, we rationalized that 2-nitroso-1-naphthol (20) could potentially differentiate radical and polar pathways. The donating capacity of the phenolic group could render the nitroso functionality reactive towards polar electrophiles to give oxime ether 21. Alternatively, radical intermediates would engage the nitroso group to arrive at hydroxylamine 22. Under the reaction conditions, only oxime ether $\mathbf{2 1}$ was formed in $18 \%$ yield with the remainder of the mass balance attributed to unreacted starting materials. Amine $\mathbf{2 2}$ was not detected in the reaction mixture. In addition, we employed density functional theory (DFT) calculations with energies refined at the B2PLYP-D3/def2TZVPPD level of theory ${ }^{37}$ to assess the thermodynamics of

closed- and open-shell pathways for activation of $t$-BuOH by $\mathrm{FeCl}_{3}$ through a polar pathway or $\mathrm{FeCl}_{2}$ through a radical pathway using equations $1\left(\Delta \mathrm{G}^{\circ} / \Delta \mathrm{H}^{\circ}=15.8 / 18.2 \mathrm{kcal} \cdot \mathrm{mol}^{-1}\right)$ and $2\left(\Delta \mathrm{G}^{\circ} / \Delta \mathrm{H}^{\circ}=42.5 / 46.7 \mathrm{kcal} \cdot \mathrm{mol}^{-1}\right)$, respectively:

$$
\begin{aligned}
& t-\mathrm{BuOH}+\mathrm{FeCl}_{3} \rightarrow t-\mathrm{Bu}^{+}+\left[\mathrm{FeCl}_{3} \mathrm{OH}\right]^{-} \\
& t-\mathrm{BuOH}+\mathrm{FeCl}_{2} \rightarrow t-\mathrm{Bu} \cdot+\mathrm{FeCl}_{2} \mathrm{OH}
\end{aligned}
$$

The reaction between $t-\mathrm{BuOH}$ and $\mathrm{FeCl}_{3}$ to form tert-butyl cation is computed to be lower in free energy by $26.7 \mathrm{kcal} \cdot \mathrm{mol}^{-}$ 1 suggesting it is far more likely to occur. Considering the reaction is run in the presence of a strong Brønsted acid, we also examined how protonation of the alcohol group affects these energetics. First, protonation of the alcohol group by $\mathrm{HCl}$ is predicted to be significantly thermodynamically uphill $\left(\Delta \mathrm{G}^{\circ}=\right.$ $\left.28.8 \mathrm{kcal} \cdot \mathrm{mol}^{-1}\right)$. The free energy for subsequent cleavage of the $\mathrm{C}-\mathrm{O}$ bond in the presence of $\mathrm{FeCl}_{3}$ and $\mathrm{FeCl}_{2}$ are computed using eq. $3\left(\Delta \mathrm{G}^{\circ} / \Delta \mathrm{H}^{\circ}=-5.8 /-4.0 \mathrm{kcal} \cdot \mathrm{mol}^{-1}\right)$ and $4\left(\Delta \mathrm{G}^{\circ} / \Delta \mathrm{H}^{\circ}=\right.$ $\left.40.1 / 44.1 \mathrm{kcal} \cdot \mathrm{mol}^{-1}\right)$ :

$$
\begin{aligned}
& t-\mathrm{BuOH}_{2}{ }^{+}+\mathrm{FeCl}_{3} \rightarrow \mathrm{tBu}^{+}+\mathrm{FeCl}_{3} \mathrm{OH}_{2} \\
& t-\mathrm{BuOH}_{2}{ }^{+}+\mathrm{FeCl}_{2} \rightarrow \mathrm{tBu} \cdot+\left[\mathrm{FeCl}_{2} \mathrm{OH}_{2}\right]^{+}
\end{aligned}
$$

The reaction in eq. 3 is lower in free energy than the reaction protonating the alcohol renders the polar pathway even more likely. Based on these studies, we propose this reaction proceeds via a polar Friedel-Crafts type mechanism.

From here, we next sought to gain insight into the course of the reaction (Figure 5). We first computed the association complexes between $\mathrm{FeCl}_{3}$ and other components in the reaction. All attempts to locate a structure for " $\mathrm{HFeCl}_{4}$ " through coordination of $\mathrm{HCl}$ to the iron center of $\mathrm{FeCl}_{3}$ led to dissociation of the $\mathrm{HCl}$ upon optimization. This indicates that $\mathrm{HFeCl}_{4}$ is not a well-defined minimum on the potential energy surface at this level of theory. In addition, the formation of the $\mathrm{HCl}---\mathrm{FeCl}_{3}$ association complex is uphill $\left(\Delta \mathrm{G}^{\circ} / \Delta \mathrm{H}^{\circ}=5.5 /-1.8 \mathrm{kcal} \cdot \mathrm{mol}^{-1}\right)$. We found that the most stable 1:1 complex is between $t$-BuOH and $\mathrm{FeCl}_{3}\left(t-\mathrm{BuOH}+\mathrm{FeCl}_{3} \rightarrow t-\mathrm{BuOH}-\mathrm{FeCl}_{3}\right)$ where $\Delta \mathrm{G}^{\circ} / \Delta \mathrm{H}^{\circ}=$ $-10.4 /-21.7 \mathrm{kcal} \cdot \mathrm{mol}^{-1}$. Direct ionization from this complex to form the tert-butyl cation is significantly thermodynamically

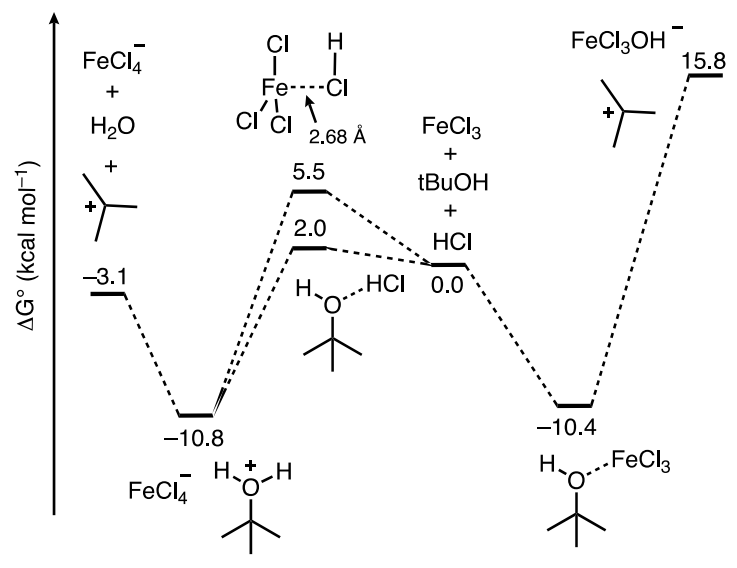

Figure 5. Free energy profile computed using DFT calculations for the course of ionization of $t-\mathrm{BuOH}$ in the presence of the $\mathrm{FeCl}_{3} / \mathrm{HCl}$ acid pair and $\mathrm{FeCl}_{3}$. 
uphill $\left(\Delta \mathrm{G}^{\circ} / \Delta \mathrm{H}^{\circ}=26.2 / 39.9 \mathrm{kcal} \cdot \mathrm{mol}^{-1}\right)$, which is consistent with how $\mathrm{FeCl}_{3}$ has not been successful in catalyzing transformations with unactivated tert-alkanols. ${ }^{17,18,38}$ It is also not clear what role $\mathrm{HCl}$ would play in this process. Alternatively, $\mathrm{HCl}$ association with $t$ - $\mathrm{BuOH}$ to form a hydrogen bonded complex is slightly unfavored $(t-\mathrm{BuOH}+\mathrm{HCl} \rightarrow t-\mathrm{BuOH}-\mathrm{HCl})$ where $\left(\Delta \mathrm{G}^{\circ} / \Delta \mathrm{H}^{\circ}=2.0 /-5.4 \mathrm{kcal} \cdot \mathrm{mol}^{-1}\right)$. However, putting $\mathrm{FeCl}_{3}$ near the $\mathrm{HCl}$ and optimizing the geometry results in spontaneous protonation of the alcohol to form the $t-\mathrm{BuOH}_{2}{ }^{+}--\left[\mathrm{FeCl}_{4}\right]^{-}$ion pair. The ion pair is lower in free energy than the hydrogen bonded complex by $12.8 \mathrm{kcal} \cdot \mathrm{mol}^{-1}$, indicating that $\mathrm{FeCl}_{3}$ facilitated protonation of the alcohol is competitive with direct coordination of $\mathrm{FeCl}_{3}$ to $t-\mathrm{BuOH}$. From the ion pair, ionization to the tert-butyl cation is only $7.7 \mathrm{kcal} \cdot \mathrm{mol}^{-1}$ uphill. Thus, the combination of $\mathrm{FeCl}_{3}$ and $\mathrm{HCl}$ provides a low energy pathway to the formation of the reactive tert-butyl cation.

The results in Figure 5 imply that the basis for the $\mathrm{FeCl}_{3}$ Lewis acid additive increases the $\mathrm{Br} \varnothing$ nsted acidity of $\mathrm{HCl}$ despite the lack of a discrete structure for " $\mathrm{HFeCl}_{4}$ ". This is reminiscent of the $\mathrm{HF} / \mathrm{BF}_{3}$ pair that is sometimes referred to $\mathrm{HBF}_{4}$, for which there is no expected discrete structure. ${ }^{39}$ We next sought to quantify the extent of increased Brønsted acidity imparted by the inclusion of the Lewis acid additive for several Brønsted acid/Lewis acid (HA/L) pairs. We used the reaction shown in equation 5, where $H A$ is the Brønsted acid, $L$ represents the Lewis acid additive, and HA-L represents a complex formed between them:

$$
H A-L+A^{-} \rightarrow H A+A-L^{-}
$$

The $H A / L$ pairs studied are those tested in this study, $\mathrm{HCl} / \mathrm{FeCl}_{3}, \mathrm{HBr} / \mathrm{FeBr}_{3}, \mathrm{CF}_{3} \mathrm{COOH} / \mathrm{FeCl}_{3}$, as well as $\mathrm{HF} / \mathrm{BF}_{3}$ ( $\mathrm{Table}$ 3). It should be noted that for the binary mineral acids studied, the $\mathrm{HA}-\mathrm{L}$ is not stable relative to the separated $\mathrm{HA}$ and $\mathrm{L}$ species and so the energy calculated from equation 5 corresponds with the complexation energy between $\mathrm{A}^{-}$and $\mathrm{L}$.

The data in Table 3 show that the added Lewis acid has a substantial effect on the acidity of the Brønsted acids. $\mathrm{FeCl}_{3}$ provides more stabilization to chloride ion than to trifluoroacetate $\left(\Delta \Delta \mathrm{G}^{\circ}=-6.7 \mathrm{kcal} \cdot \mathrm{mol}^{-1}\right)$ and more stabilization than $\mathrm{FeBr}_{3}$ provides to bromide ion $\left(\Delta \Delta \mathrm{G}^{\circ}=-2.8 \mathrm{kcal} \cdot \mathrm{mol}^{-1}\right)$. In addition, the biggest increase is achieved for the $\mathrm{HF} / \mathrm{BF}_{3}$ pair. These results suggest a synergistic effect between the conjugate base and Lewis acid may be a significant factor for determining

Table 3. Free energy calculated from equation 5 to estimate the increased Bronsted acidity for Bronsted acid/Lewis acid pairs (HA/L) discussed in this study.

\begin{tabular}{ccc}
\hline $\mathrm{HA} / \mathrm{L}$ & $\begin{array}{c}\Delta \mathrm{G}^{\circ} \mathrm{Eq} .5 \\
\left(\mathrm{kcal} \mathrm{mol}^{-1}\right)\end{array}$ & $\Delta \mathrm{pK}_{\mathrm{a}}$ \\
\hline $\mathrm{HCl} / \mathrm{FeCl}_{3}$ & -31.4 & 23 \\
$\mathrm{HBr} / \mathrm{FeBr}_{3}$ & -28.6 & 21 \\
$\mathrm{CF}_{3} \mathrm{COOH} / \mathrm{FeCl}_{3}$ & -24.7 & 18 \\
$\mathrm{HF} / \mathrm{BF}_{3}$ & -47.5 & 35 \\
\hline
\end{tabular}

the increase in Brønsted acidity.

We next used eq. 6 to gain a better sense for the acidity of the $\mathrm{HA} / \mathrm{L}$ pairs relative to $\mathrm{HCl} / \mathrm{FeCl}_{3}$ to assess their overall reactivity:

$$
\mathrm{HA}-\mathrm{L}+\mathrm{FeCl}_{4}^{-} \rightarrow[\mathrm{A}-\mathrm{L}]^{-}+\mathrm{HCl}+\mathrm{FeCl}_{3} .
$$

For the $\mathrm{HBr} / \mathrm{FeBr}_{3}$ pair, $\Delta \mathrm{G}^{\circ} / \Delta \mathrm{H}^{\circ}=-2.9 /-3.2 \mathrm{kcal} \cdot \mathrm{mol}^{-1}$, which is consistent with our experimental results suggesting this pair to be more reactive. However, this value is about half as much as one would expect based on the relative $\mathrm{pK}_{\mathrm{a}}$ values of $\mathrm{HCl}$ and $\mathrm{HBr}$ in $\mathrm{DCE},\left(\triangle \mathrm{pK}_{\mathrm{a}}[\mathrm{DCE}], \mathrm{HBr}-\mathrm{HCl}=4.5\right) .40$ The other two combinations are predicted to be less reactive than $\mathrm{HCl} / \mathrm{FeCl}_{3}$, where the $\mathrm{CF}_{3} \mathrm{COOH} / \mathrm{FeCl}_{3}$ and $\mathrm{HF} / \mathrm{BF}_{3}$ combinations give $\Delta \mathrm{G}^{\circ} / \Delta \mathrm{H}^{\circ}=8.4 / 16.8$ and $7.5 / 7.1 \mathrm{kcal} \cdot \mathrm{mol}^{-1}$, respectively. The former case is consistent with experimental results from Table 1 (entry 2) showing no product formation with the $\mathrm{CF}_{3} \mathrm{COOH} / \mathrm{FeCl}_{3}$ pair. The use of $\mathrm{HBF}_{4}(2.5 \mathrm{~mol} \%)$ as the catalyst resulted in only trace product formation $\left(<5 \%\right.$ by ${ }^{1} \mathrm{H} N M R$ analysis). These results suggest that the pairing of a Lewis acid with a Brønsted acid generally increases the Brønsted acidity significantly in organic media and that careful choice of the pairing could provide a level of control over the overall reactivity of the pair.

\section{Conclusions}

We have detailed mild and operationally simple reaction conditions to achieve tert-alkylations of aromatic systems with tertiary alkylperoxides and alcohols in forming all-carbon quaternary centers through synergistic Brønsted/Lewis acid catalysis. These reactions fill a gap in the Friedel-Crafts alkylation literature by enabling the use of tertiary aliphatic alcohols that lack stabilizing aryl, alkenyl, and alkynyl substituents. ${ }^{41}$ We expect this approach will prove to be practical in installing quaternary carbon centers when orchestrated into synthesis plans that take advantage of $\mathrm{C}-\mathrm{O}$ bonds (e.g., triflyl and methoxy groups) for cross-coupling applications. ${ }^{42}$ The use of cost-effective and readily-available iron, alcohol and arene reagents render this methodology advantageous for all-carbon quaternary center and $\mathrm{C}\left(\mathrm{sp}^{2}\right)-$ $\mathrm{C}\left(\mathrm{sp}^{3}\right)$ bond synthesis.

\section{Author Contributions}

A. P., M. C., R. C., and L. G. conducted the catalysis experiments and the characterization of the compounds. B. E. H. designed and performed the computational experiments. K. G. M. K conceived, designed, and oversaw the project. All authors contributed to writing and editing the manuscript.

\section{Conflicts of interest}

There are no conflicts to declare. 


\section{Acknowledgements}

UCR and Westmont College are gratefully acknowledged for startup funds. The Agilent 6545 Q-TOF LC/MS and Bruker D8 Venture X-ray diffractometer are funded by NSF grants CHE1828782 and MRI-1919677. We thank Dr. Jie Zhou (UCR) and Dr. Felix Grun (UCl) for accurate mass analyses and Dr. Charlene Tsay (UCR) for X-ray crystallographic analysis. Computational resources on the Stampede2 supercomputer at the Texas Advanced Computing Center (TACC) were obtained through the Extreme Science and Engineering Discovery Environment (XSEDE) program through allocation TG-CHE190033.

\section{References}

1 a) F. Lovering, J. Bikker, C. Humblet, J. Med. Chem., 2009, 52, 6752-6756; b) T. J. Ritchie, S. J. F. Macdonald, Drug Discov. Today, 2009, 14, 1011-1020.

2 a) O. Méndez-Lucio, J. L. Medina-Franco, Drug Discov. Today, 2017, 22, 120-126; b) A. W. Dombrowski, N. J. Gesmundo, A L. Aguirre, K. A. Sarris, J. M. Young, A. R. Bogdan, M. C. Martin, S. Gedeon, Y. Wang, ACS Med. Chem. Lett., 2020, 11, 597-604.

3 a) R. Long, J. Huang, J. Gong, Z. Yang, Nat. Prod. Rep., 2015 32, 1584-1601; b) T. Ling, F. Rivas, Tetrahedron, 2016, 72 6729-6777; c) T. T. Talele, J. Med. Chem., 2020, 63, 1329113315; d) C. Zhang, F. Li, Y. Yu, A. Huang, P. He, M. Lei, J. Wang, L. Huang, Z. Liu, J. Liu, Y. Wei, J. Med. Chem., 2017, 60, 3618-3625.

4 For selected reviews, see: a) C. J. Douglas, L. E. Overman, PNAS, 2004, 101, 5363-5367; b) K. W. Quasdorf, L. E. Overman, Nature, 2014, 516, 181-191; c) J. P. Das, I. Marek, Chem. Commun., 2011, 47, 4593-4623.

5 a) C. Lohre, T. Dröge, C. Wang, F. Glorius, Chem.-Eur. J., 2011, 17, 6052-6055; b) A. Joshi-Pangu, C.-Y. Wang, M. R. Biscoe, J. Am. Chem. Soc., 2011, 133, 8478-8481.

6 S. L. Zultanski, G. C. Fu, J. Am. Chem. Soc., 2013, 135, 624-627.

7 D. N. Primer, G. A. Molander, J. Am. Chem. Soc., 2017, 139, 9847-9850.

8 X. Wang, S. Wang, W. Xue, H. Gong, J. Am. Chem. Soc., 2015, 137, 11562-11565.

9 T.-G. Chen, H. Zhang, P. K. Mykhailiuk, R. R. Merchant, C. A. Smith, T. Qin, P. S. Baran, Angew. Chem. Int. Ed., 2019, 58 2454-2458; Angew. Chem., 2019, 131, 2476-2480.

10 S. A. Green, T. R. Huffman, R. O. McCourt, V. van der Puyl, R. A. Shenvi, J. Am. Chem. Soc., 2019, 141, 7709-7714.

11 J. R. Dorsheimer, M. A. Ashley, T. Rovis, J. Am. Chem. Soc., 2021, ASAP, http://doi.org/10.1021/jacs.1c10150.

12 C. A. Luchaco-Cullis, H. Mizutani, K. E. Murphy, A. H. Hoveyda, Angew. Chem. Int. Ed., 2001, 40, 1456-1460; Angew. Chem., 2001, 113, 1504-1508.

13 a) Y. Shimizu, S.-L. Shi, H. Usuda, M. Kanai, M. Shibasaki, Angew. Chem. Int. Ed., 2010, 49, 1103-1106; Angew. Chem. 2010, 122, 1121-1124; b) D. T. George, E. J. Kuenstner, S. V. Pronin, J. Am. Chem. Soc., 2015, 137, 15410-15413; c) Y. Yamane, K. Yoshinaga, M. Sumimoto, T. Nishikata, ACS Catal. 2019, 9, 1757-1762; d) J. C. Lo, D. Kim, C.-M. Pan, J. T. Edwards, Y. Yabe, J. Gui, T. Qin, S. Gutiérrez, J. Giacoboni, M. W. Smith, P. L. Holland, P. S. Baran, J. Am. Chem. Soc., 2017, 139, 2484-2503.

14 I. lovel, K. Mertins, J. Kischel, A. Zapf, M. Beller, Angew. Chem. Int. Ed., 2005, 44, 3913-3917; Angew. Chem., 2005, 44, 39133917.

15 L. R. Jefferies, S. P. Cook, Org. Lett., 2014, 16, 2026-2029.

16 M. Rueping, R. M. Koenigs, I. Atodiresei, Chem.-Eur. J., 2010, 16, 9350-9365.
17 M. Rueping, B. J. Nachtsheim, Beilstein J. Org. Chem., 2010, 6, DOI: $10.3762 /$ bjoc6.6.

18 L. Chen, X.-P. Yin, C.-H. Wang, J. Zhou, Org. Biomol. Chem., 2014, 12, 6033-6048.

19 P. Wardman, L. P. Candeias, Radiat. Res., 1996, 145, 523-531.

20 a) C. Kim, K. Chen, J. Kim, L. Que, Jr. J. Am. Chem. Soc., 1997, 119, 5964-5965; b) M. S. Chen, M. C. White, Science, 2007, 318, 783-787.

21 B. J. Groendyke, A. Modak, S. P. Cook, J. Org. Chem., 2019, 84, 13073-13091.

22 L. Liguori, H.-R. Bjørsvik, F. Fontana, D. Bosco, L. Galimberti, F. Minisci, J. Org. Chem., 1999, 64, 8812-8815.

23 W. M. Kutz, B. B. Corson, J. Am. Chem. Soc., 1946, 68, 14771479.

24 J. F. Perez-Benito, J. Phys. Chem. A, 2004, 108, 48534858.Error! Hyperlink reference not valid.

25 H. Shalit, A. Libman, D. Pappo, J. Am. Chem. Soc., 2017, 139, 13404-13413.

26 T. Horibe, S. Ohmura, K. Ishihara, J. Am. Chem. Soc., 2019, 141, 1877-1881.

27 J. Burés, Angew. Chem. Int. Ed., 2016, 55, 2028-2031; Angew. Chem., 2016, 128, 2068-2071.

28 Y. Liu, B. Kim, S. D. Taylor, J. Org. Chem., 2007, 72, 8824-8830.

29 V. Krishnan, K. Ojha, N. C. Pradhan, Org. Proc. Res. Dev., 2002, 6, 132-137.

30 G. D. Yadav, S. B. Kamble, Chem. Eng. Res. Des., 2012, 90, 1322-1334.

31 M. Elkin, S. M. Szewczyk, A. C. Scruse, T. R. Newhouse, J. Am. Chem. Soc., 2017, 139, 1790-1793.

32 L. Wanka, K. Iqbal, P. R. Schreiner, Chem. Rev., 2013, 113, 3516-3604.

33 a) Y.-X. Lao, J.-Q. Wu, Y. Chen, S.-S. Zhang, Q. Li, H. Wang, Org. Chem. Front., 2015, 2, 1374-1378; b) H.-B. Yang, A. Feceu, D. B. C. Martin, ACS Catal., 2019, 9, 5708-5715; c) W. K. Weigel, III, H. T. Dang, H.-B. Yang, D. B. C. Martin, Chem. Commun., 2020, 56, 9699-9702.

34 A. V. Stepakov, A. P. Molchanov, R. R. Kostikov, Russ. J. Org. Chem., 2007, 43, 538-543.

35 J. F. Van Humbeck, S. P. Simonovich, R. R. Knowles, D. W. C. MacMlllian, J. Am. Chem. Soc., 2010, 132, 10012-10014.

36 Th. J. de Boer, Can. J. Chem., 1982, 60, 1602-1609.

37 Energies are computed at the B2PLYPD3/def2TZVPPD//M15L/def2-SVP level of theory. Refined energies include solvation effects with the IEF-PCM model with 1,2dichloroethane as the solvent and are corrected to a $1 \mathrm{M}$ standard state. See supporting information for full description of computational methods.

38 I. Bauer, H.-J. Knölker, Chem. Rev. 2015, 115, 3170-3387.

39 M. Juhasz, S. Hoffmann, E. Stoyanov, K.-C. Kim, C. A. Reed, Angew. Chem. Int. Ed., 2004, 43, 5352-5355.

40 a) A. Kütt, T. Rodima, J. Saame, E. Raamat, V. Mäemets, I. Kaljurand, I. A. Koppel, R. Y. Garlyauskayte, Y. L. Yagupolskii, L. M. Yagupolskii, E. Bernhardt, H. Willner, I. Leito, J. Org. Chem., 2011, 76, 391-395. b) E. Paenurk, K. Kaupmees, D. Himmel, A. Kütt, I. Kaljurand, I. A. Koppel, I. Krossing, I. Leito, Chem. Sci., 2017, 8, 6964-6973.

41 During the preparation of our manuscript, the use of $\mathrm{TfOH}$ in HFIP solvent to perform Friedel-Crafts alkylations of tertalcohols with selected arenes in excess was reported: S. Zhang, M. Vayer, F. Noël, V. D. Vuković, A. Golushko, N. Rezajooei, C. N. Rowley, D. Lebœuf, J. Moran, Chem, 2021, https://doi.org/10.1016/j.chempr.2021.10.023.

42 a) B. M. Rosen, K. W. Quasdorf, D. A. Wilson, N. Zhang, A. M. Resmerita, N. K. Garg, V. Percec, Chem. Rev., 2011, 111, 13461416. b) M. Tobisu, N. Chatani, Acc. Chem. Res., 2015, 48, 1717-1726. 